\title{
Pagelaran Budaya Jepang dalam Perspektif Dramaturgi
}

\section{Japanese Culture Performance in Dramaturgy Perspective}

\author{
Putri Ekaresty Haes* \& Nuning Indah Pratiwi \\ Program Studi Ilmu Komunikasi, Fakultas Ilmu Hukum dan Ilmu Sosial, Universitas \\ Pendidikan Nasional, Indonesia
}

Diterima: November 2019; Disetujui: November 2019; Dipublish: Desember 2019

*Coresponding Email: ekarestvhaes@undiknas.ac.id

\begin{abstract}
Abstrak
Fenomena acara televisi anime serta buku komik yang berasal dari jepang memberikan ruang bagi perkembangan budaya popular Jepang di Bali. Seni berbusana dalam budaya popular Jepang seperti Harajuku Style (yang terdiri dari Lolita, Visual Kei, Ganguro dan costum player) telah menggeser busana tradisional Jepang seperti kimono dan Yukata. Seorang costum player mengagumi karakter anime, manga atau cosplayer tertentu dan mencoba menghadirkan sosok karakter tersebut dalam beberpa pagelaran budaya Jepang yang dilaksanakan di kota Denpasar dan Kecamatan Badung. Adapun tujuan dari penelitian ini adalah untuk mengetahui panggung depan (front stage) dan panggung belakang (back stage) dari pada costum player tersebut. Penelitian ini merupakan penelitian kualitatif, dengan menggunakan teknik pengumpulan data berupa observasi, wawancara dan teknik dokumentasi. Dalam Hasil penelitian terungkap bahwa dalam perspektif dramaturgi yang menerangkan tentang keberadaan panggung dalam kehidupan manusia memberikan penjelasan bahwa antara panggung panggung depan (front stage) dan panggung belakang (back stage) seorang cosplayer merupakan dua sisi yang berbeda, bahkan bertolak belakang, namun tidak jarang memiliki kesamaan karakter. Penyajian gaya busana para custom player sangat beragam (disesuaikan dengan tokoh) serta penuh dengan kreatifitas sehingga selalu menjadi pusat perhatian dalam pagelaran budaya Jepang yang dilakukan di The Japan Pagelaran of Udayana (D’JaFU), CLAS: H Bali Sakura Matsuri.
\end{abstract}

Keywords: Budaya Populer Jepang, Custom Player, Front Stage, Back Stage

\begin{abstract}
The phenomenon of anime television shows and comic books originating from Japan provides space for the development of Japanese popular culture in Bali. The art of dress in Japanese popular cultures such as Harajuku Style (such as Lolita, Visual Kei, Ganguro and the costume player) has shifted traditional Japanese clothing such as kimono and Yukata. A cospalyer admires a certain anime, manga or costume player character and tries to present the character in several Japanese cultural performances held in the city of Denpasar and Badung Sub-district. The purpose of this research is to study the front stage (backstage) of the costume players. This research is qualitative, using data collection techniques such as observation, interviews and documentation techniques. The result from this research explained that on dramaturgy perspective the existence of stage in human life between the front stage and the backstage of a costume player is two different sides, even contradictory, but some of them had the same character. The Presentation of the Japanese's fashion styles are very disserving (adapted from the characters) and full of creativities, so all the costume player will be the center of attention in Japanese cultural performances conducted in The Japan Pagelaran of Udayana (D'JaFU), CLAS: H Bali Sakura Matsuri, dan Fella Market Cosplay Competition.
\end{abstract}

Keywords: Japanese popular culture, Custom Player, Front Stage, Back Stage

How to Cite: Haes, P.E. \& Pratiwi, N.I. (2019). Pagelaran Budaya Jepang dalam Perspektif Dramaturgi. Journal of Education, Humaniora and Social Sciences (JEHSS). 2(2): 127-131. 
Putri Ekaresty Haes \& Nuning Indah Pratiwi, Pagelaran Budaya Jepang dalam Perspektif Dramaturgi

\section{PENDAHULUAN}

Pakaian di jaman sekarang tidak lagi dipandang hanya sebagai penutup dan pelindung tubuh manusia dari cuaca atau memiliki hanya berfungsi sebagai kesopanan (modesty function) saja, Carlyle dalam Barnard (2011) menyebutkan bahwa pakaian merupakan perlambang jiwa (emblems of the soul), pakaian mengkomunikasikan kelas sosial, afiliasi politik dan budaya dari pemakainya, sehingga kita dengan mudah mengenali identitas nasional dan kultural seseorang dari pakaian yang mereka kenakan. Lebih dari itu, di era millennial saat ini pakaian bukan sekedar alat untuk mengekspresikan sebuah pesan namun sering dianggap sebagai alat untuk memanipulasi tubuh seseorang, membangun habitus pribadi dan menciptakan citra pribadi dalam masyarakat sehingga dapat menunjukkan kualitas gaya hidup seseorang. Pakaian menjadi dasar dalam pembentukan kelompok sosial dalam masyarakat yang mengkontruksikan identitas budaya tertentu dalam masyarakat seperti J-Pop Uapanese Pop Culture).

J-Pop (Japanese Pop Culture), tidak hanya tentang film, drama, Anime, Manga, musik tetapi juga J-Fashion (Japanese Fashion) atau seni berpakaian masyarakat Jepang. Seni berpakaian masyarakat Jepang yang terkenal adalah Kimono dan Yukata, namun dengan banyaknya masyarakat dunia yang berkunjung ke Jepang terjadilah proses akulturasi budaya sehingga banyak model J-Fashion (Japanese Fashion) yang mengalami perkembangan salah satunya adalah para pecinta anime, manga, dan video games. Kelompok ini sering disebut sebagai cosplayer. Permainan kostum atau Cosplay (コスプレ Kosupure) merupakan istilah dalam bahasa Inggris buatan Jepang ( $\underline{\text { wasei-eigo }}$ ) yang berasal dari gabungan kata "costume" (kostum) dan "play" (bermain). Di negara Jepang cosplay ini banyak dijumpai pada saat perkumpulan penggemar atau dōjin circle atau pada saat menghadiri konser dari sebuah group musik yang bergendre visual Kei maupun perkumpulan lainnya yang memiliki kesukaan pada satu tokoh, music, genre yang sama.

Seorang cosplayer sejatinya mengagumi karakter yang ada di anime, manga atau game tertentu dan kemudian akan mencoba meniru segala hal dari karakter tersebut. Mulai dari kostum hingga sifat pada tokoh Anime itu sendiri. Costum Player pada umumnya tergabung dalam sebuah komunitas cosplay tertentu yang memiliki kesamaan pada tokoh anime, manga atau games. Oleh karena gaya pakaian yang sangat unik, para 246 http://mahesainstitute.web.id/ojs2/index.php/jehss 
costum player ini seringkali menjadi pusat perhatian setiap kali muncul dalam masyarakat. Kroski (2015) menyebutkan bahwa seorang costume player memiliki referensi sendiri ketika memilih sebuah tokoh, tokoh tersebut mereka temukan dari berbagai bentuk aliran seperti karya fiksi ilmiah, komik, animasi jepang yang tampil pada layar televisi maupun film, permainan video games hingga sebuah karya literatur. Para cosplayer akan memilih tokoh yang merepresentasikan kepribadian mereka, sehingga tidak jarang mereka akan membuat kostum karakter yang sama dengan sangat detail, beberapa cosplayer ini juga mendaur ulang kostum mereka dengan menambah atau mengurangi detail yang ada pada desain kostum. Menurut Widjiningsih dalam Riyanto (2003) desain kostum ialah rancangan busana yang didalam bentuk dan fungsinya, memahami dan mengetahui nilai-nilai yang berkaitan dengan topik seperti filosofi, histori, etis, estetik busana (kostum)/gerak dan nilai religi. Bukan hanya sekedar pakaian, namun sudah menjadi suatu pemaknaan dan peran dari seseorang yang memakai kostum.

Cosplayer yang ada di Indonesia sendiri memiliki segudang prestasi di tingkat internasional seperti Yesaya Marito dan Rizki Karismana yang berhasil meraih juara ketiga pada ajang World Cosplay Summit di Nagoya, Jepang pada tahun 2012 silam. Rian Cahyadi dan Wijaya yang juga dari mewakili Indonesia dengan menjadi CosplayerRaiden dan Samuel dari GameMetal Gear Rising dalam ajang Anime Pagelaran Asia di Singapura. Fenomena Cosplayer pada akhirnya juga ikut tersebar ke berbagai daerah di Indonesia termasuk Bali. Berdasarkan informasi yang ada pada akun resmi konsulat jendral Jepang di Denpasar (denpasar.id.emb-japan.go.jp) pada tahun 2011 diadakan lomba cosplayer pertama di Bali yaitu Bunkasai (Pagelaran Budaya Jepang) yang diadakan oleh Yamaha. Sejak saat itu banyak pagelaran budaya Jepang yang diadakan setiap tahunnya di Bali seperti The Japan Pagelaran of Udayana (D'JaFU), Bali Japan Matsuri, Indonesia Cosplay Grand Prix, Dalam pagelaran budyaa Jepang tersebut tidak hanya memamerkan cosplayer saja tetapi juga menghadirkan budaya Jepang lainnya antara lain dengan makanan, aksesoris, dan pakaian tradisional yaitu komono dan Yukata.

Perspektif dramaturgi erat kaitannya dengan seni teater, dimana aktor yang memerankan tokoh tertentu akan total membawakan karakter tokoh tersebut yang sangat jauh berbeda dengan kepribadian aktor tersebut. Aktor harus dapat melakonkan secara baik dan benar karakter tokoh tersebut, agar orang lain yang melihatnya dapat 
Putri Ekaresty Haes \& Nuning Indah Pratiwi, Pagelaran Budaya Jepang dalam Perspektif Dramaturgi

mengerti ceritra dibalik karakter tokoh tersebut. Goffman dalam Ritzer (2012) mengatakan bahwa kehidupan sosial manusia dibagi menjadi dua bagian, yaitu panggung depan (Front Stage) dan panggung belakang (Back Stage). Panggung depan adalah sandiwara yang dilakukan secara umum dengan cara yang formal untuk berperan seperti aktor dalam drama panggung yang dibagi menjadi (personal front) dan tempat (setting). personal front mencangkup bahasa verbal dan non verbal dari sang aktor, sedangkan latar belakang mengacu pada tempat atau situasi (scene) yang harus ada ketika aktor sedang melakukan pertunjukan. Selanjutnya Goffman dalam Ritzer (2012) menyatakan bahwa panggung belakang (Back Stage) adalah tempat tersembunyi dari pandangan khalayak (audience). Hal ini bertujuan untuk melindungi rahasia sang aktor dan aksi panggung akan sulit apabila ada audiens yang memasuki panggung belakang tersebut.

\section{METODE PENELITIAN}

Penelitian ini menggunakan desain penelitian kualitatif, yaitu suatu pendekatan atau penelusuran untuk mengeksplorasi dan memahami suatu gejala sentral (Creswell dalam Rukajat (2018). Desain penelitian kualitatif ini digunakan agar dapat memberikan pemahaman lebih dalam pada fenomena pagelaran budaya Jepang cosplayer dalam perspektif Dramaturgi. Peneliti menggunakan tiga teknik pengumpulan data, yaitu Observasi partisipan, dokumentasi dan wawancara mendalam (indepth interview) agar mendapatkan informasi yang akurat terkait dengan fenomena yang diteliti. Sedangkan teknik penentuan informan penelitian menggunakan teknik snowball. Nurdiani (2014) mengatakan bahwa teknik snowball sampling adalah suatu metode untuk mengidentifikasi, memilik, dan mengambil sampel dalam suatu jaringan atau rantai hubungan yang menerus atau metode sampling dimana sampel diperoleh melalui proses bergulir dari satu informan ke informan yang lainnya, biasanya metode ini digunakan untuk menjelaskan pola-pola sosial atau komunikasi (sosiometrik) pada sebuah komunitas tertentu. Sedangkan teknik pemeriksaan keabsahan data menggunakan trianggulasi yaitu trianggulasi sumber, trianggulasi waktu dan trianggulasi teknik.

\section{HASIL DAN PEMBAHASAN}

Penelitian yang dilakukan pada dua pagelaran budaya Jepang yang diselenggarakan yaitu The Japan Pagelaran of Udayana (D'JaFU) dan CLAS: H (Cosplay Live Action Show 2盘
248 http://mahesainstitute.web.id/ojs2/index.php/jehss 
Hybrid). The Japan Pagelaran of Udayana (D'JaFU) yang merupakan pagelaran budaya Jepang yang dilaksanakan oleh himpunan mahasiswa sastra Jepang dari Universitas Udayana Denpasar. Awalnya The Japan Pagelaran of Udayana (D'JaFU) dilaksanakan pertama kali di RRI (Radio Republik Indonesia) dengan nama Kohaku. Dalam pagelaran budaya tersebut juga diadakan banyak kegiatan lainnya yaitu: lomba story telling, lomba menulis hiragana dan katakana, lomba fan art, lomba majalah dinding (Mading), lomba band anisong, lomba cosplay, dan pagelaran kebudayaan Jepang.

CLAS: H (Cosplay Live Action Show Hybrid) merupakan salah satu dari sub acara pagelaran Jepang Ennichisai. (www.ennichisaiblokm.com) kegiatan ini berorientasi pada Cosplayer. CLAS: H (Cosplay Live Action Show Hybrid) juga terkenal karena menyelenggarakan kompetisi Cosplayer bertaraf nasional dengan menggunakan aturan standar internasional yang ketat. Kompetisi telah diadakan setiap tahun sejak 2011. CLAS: H (Cosplay Live Action Show Hybrid) juga dikaitkan dengan World Cosplay Summit (WCS), kompetisi kinerja Cosplay dunia sejak 2012. Sejak 2011 CLAS: H (Cosplay Live Action Show Hybrid) telah menyelenggarakan acara budaya J Pop di beberapa kota seperti, Medan (Sumatra), Bandung (Jawa Timur), Yogyakarta (Jawa Tengah), Surabaya (Jawa Timur). Sedangkan di tahun 2019 ini CLAS: H (Cosplay Live Action Show Hybrid) akan dilaksanakan di Bali, Malang, Medan, Yogyakarta dan Bandung. Tema yang diangkat dalam pagelaran budaya Jepang tahun 2019 ini adalah Bali Sakura Matsuri yang dilaksanakan pada bulan Februari silam dengan mengusung kegiatan utama yaitu ICGP (Indonesia Cosplay Grand Prix) Bali. Kegiatan ini merupakan ajang bagi para cosplayer untuk menampilkan kostum mereka diatas panggung.

Dari kedua pageralan budaya Jepang tersebut mendapatkan hasil bahwa sebagai seorang cosplayer, identitas diri mereka sebagai seorang tokoh hanya berlangsung pada saat mereka berpakain seperti tokoh tersebut, sedangkan dalam keseharian mereka pakaian yang mereka gunakan sangat jauh berbeda. Hasil wawancara pada beberapa informan mengatakan bahwa Make-up, pakaian seksi hanya mereka gunakan pada saat memerankan tokoh yang mereka sukai, sedangkan dalam keseharian mereka disesuaikan dengan pekerjaan dan keseharian mereka.

Ibrahim (2011) mengungkapkan bahwa pakaian merupakan sarana seseorang dalam mengkomunikasikan, karena pesan menyampaikan pesan artifaktual yang bersifat nonverbal kepada khalayak. Dalam sebuah pagelaran budaya Jepang kostum menjadi 
penting karena akan memberikan pemahaman tentang Jepang. Sedangkan Kroski (2015) mengatakan bahwa Cosplayer find inspirations from different outlets and genres. Seorang cosplayer memiliki alasan tersendiri ketika memilih sebuah karakter, beberapa dari mereka akan memilih karakter yang dianggap merepresentasikan kepribadian mereka. Para pelaku cosplay tidak membatasi diri dalam mengimajinasikan karakter mereka, karena kostum tersebut menciptakan indentitas diri yang hendak dikomunikasikan oleh para pelakunya. Dalam identitas diri menuru Baumeister (1987) dalam Ardhani, Wulan dan Malau (2017) identitas dibagi menjadi kontinuitas berarti makna yang sama dalam berbagai waktu dan diferensiasi yang artinya membedakan diri seseorang dengan orang lain.

Pertunjukan drama, teater dan pertunjukkan fiski diatas panggung merupakan beberapa hal yang melatarbelakangi munculnya istilah dramaturgi. Orang-orang yang memerankan tokoh-tokoh tersebut memberikan ceritra dari drama yang disajikan. Perspektif dramaturgi menurut Widodo (2010) merupakan sebuah pandangan yang menjelaskan bahwa di dalam kegiatan interaksi satu sama lain sama halnya dengan pertunjukkan sebuah drama. Manusia adalah aktor utama yang menampilkan lakon atau karakter yang berbeda dalam berinteraksi dengan manusa lainnya. Perbedaan tersebut tergantung pada lakon apa yang sedang dimainkan oleh manusia tersebut. Dalam perspektif dramaturgi Goffman panggung depan (front Stage) merupakan sandiwara yang dibuat manusia dengan cara berperan seperti aktor di dalam drama panggung. Goffman dalam Ritzer (2012) panggung depan dibagi menjadi personal front (penampilan dan sikap) dan setting. Penampilan mengarah pada sesuatu yang menceritakan status sosial kepada khalayak (audience) dan sikap menceritakan tipe peran yang dimainkan oleh aktor. Sedangkan setting mengacu pada suatu tempat atau situasi saat melakukan petunjukkan.

Dari hasil penelitian yang dilakukan pada dua pagelaran budaya Jepang yang dilaksanakan di Bali dalam perspektif Dramaturgi maka dapat diketahu bahwa penampilan dan sikap cosplayer berbuah ubah disesuaikan dengan karakter anime, manga atau games yang mereka bawakan. Beberapa pelaku cosplay juga melakukan transcosplay/crossdeser yang meniru sebuah karakter yang sangat bertolak belakang dengan jenis kelaminnya. Banyak hal yang melatarbelakangi seseorang menjasi pelaku cosplay disamping ketertarikan pada karakter anime, manga atau games beberapa 2 震 http://mahesainstitute.web.id/ojs2/index.php/jehss mahesainstitut@gmail.com 250 
cosplayer mengaku bahwa mereka awalnya hanya membantu cosplayer lainnya, beberapa diantara juga karena orang tua sangat mendukung kegiatan karena banyak nilai positif didalamnya. Selain itu pada panggung depan (front Stage) Goffman juga menyatakan tentang perilaku yaitu upaya yang dilakukan oleh pada aktor untuk menyampaikan kesan yang dekat dengan audience yang berbeda dengan kesan yang sebenarnya. Karakteristik tokoh anime, manga atau games yang diperankan oleh beberapa cosplayer merupakan profesionalisme yang mereka lakukan terhadap idola mereka, oleh karena itu para cosplayer ini akn membuat kostum karakter tersebut dengan sangat mendetail, selain itu pada saat tampil di pegelaran budaya Jepang, para cosplayer juga menjaga kredibilitas ketokohan mereka didepan audience.

Panggung belakang (back stage) menurut Goffman dalam Ritzer (2012) merupakan tempat tersembunyi dari pandangan orang (audience). Goffman menambahkan bahwa seorang aktor mengharapkan bahwa audience panggung pertunjukkan mereka berbeda dengan panggung belakang. Sedangkan menurut Mulyana (2010) panggung belakang (Back Stage) merupakan ruang privat yang orang lain tidak mengetahuinya, tempat seseorang atau sekelompok orang yang leluasa menampilkan karakter aslinya dan juga wilayah dimana seseorang bisa mempersiapkan segala atribut yang akan digunakan untuk "pertunjukan" di panggung depan (Front Stage). Panggung belakang dalam penelitian ini merupakan karakter atau kepribadian yang dimiliki oleh para cosplayer tersebut.

Berdasarkan hasil penelitian, dijelaskan bahwa beberapa cosplayer memiliki karakteristik yang berbeda, walaupun beberapa diantara mereka memiliki hal yang sama dengan tokoh yang mereka mainkan. Panggung belakang (back stage) erat kaitannya dengan konsep diri dan pengelolaan kesan seseorang. Agustini (2006) dalam Venus dan Helmi (2010) menjelaskan bahwa konsep diri berpengaruh besar terhadap tingkah laku seseorang. Tingkah laku seseorang tersebut sangat berkaitan dengan gagasan-gagasan tentang dirinya sendiri. Lebih lanjut Agustin (2006) mengemukakan bahwa konsep diri merupakan kerangka acuan (frame of reference) seseorang ketika berinteraksi dengan lingkungan. Pada cosplayer memiliki kerangka acuan (frame of reference) yang sangat berbeda dengan panggung depan (front Stage) mereka. 
Putri Ekaresty Haes \& Nuning Indah Pratiwi, Pagelaran Budaya Jepang dalam Perspektif Dramaturgi

\section{SIMPULAN}

Berdasarkan hasil penelitian yang telah diperoleh dari dua pagelaran budaya Jepang yang dilakukan di Bali yaitu The Japan Pagelaran of Udayana (D'JaFU) dan CLAS: H (Cosplay Live Action Show Hybrid) maka dapat disimpulkan bahwa bagi cosplayer peran atau lakon panggung depan (front Stage) adalah tokoh atau karakter anime, manga atau games yang mereka perankan. Karakter anime, manga atau games secara total (melalui kostum dan atribut) ditampilan secara profesional melalui pendalaman karakter tokoh yang mereka pilih, sedangkan panggung belakang (back stage) mereka adalah kepribadian mereka setiap hari. Lakon yang telah mereka lakukan sebelum mereka terjun menjadi seorang cosplayer.

\section{DAFTAR PUSTAKA}

Agustiani, H. (2006). Psikolgi Perkembangan (Pendekatan ekologi Kaitannya dengan Konsep Diri dan Penyesuaian Diri pada Remaja). Bandung: Refika Aditama.

Ardhani, S.R. Wulan, R.R. Malau, M.R. (2017). Identitas Diri Pelaku Cosplayer (Studi Fenomenologi Cosplayer Di Komunitas Cosplay Bandung). e-Proceeding of Management: Vol.4, No.3. hal. 3283. Jurnal ini diakses pada tanggal 21 Agustus 2019 pada https: Llibraryeproceeding.telkomuniversitv.ac.id/index.php/management/article/view/5106

Budyatna, M. (2011). Teori Komunikasi Antarpribadi Sebuah Pengantar. Cetakan Pertama. Jakarta: Prenada Media Group.

Ghufron, M.N. (2011). Teori-teori Psikologi. Yogyakarta: ArRuzz Media.

Hasan, S.H. (2010). Pengembangan Pendidikan Budaya dan Karakter Bangsa. Jakarta: Kemendiknas Balitbang Puksur.

Hasanah, N. \& Meirisyah, E. (2015). Profil Tiga Cosplayers pada Komunitas Sebagai Pembentuk Identitas Diri Remaja, Anthropos: Jurnal Antropologi Sosial dan Budaya Journal of Social and Cultural Anthropology), 1 (1): 80-86.

Ibrahim, I.S. (2011). Budaya Populer Sebagai Komunikasi. Yogyakarta: Jalasutra.

Ibrahim, I.S. (2011). Fashion sebagai Komunikasi. Yogyakarta: Jalasutra.

Kellner, D. (2010). Budaya Media. Yogyakarta: Jalasutra.

Kroski, E. (2015). Cosplay in Libraries: How to Embrace Costume Play in Your Library. London: The Rowman and Littlefield Publishing Group

Krulos, T. (2013). Heroes in the Night: Inside the Real Life Superhero Movement. Chicago: Chicago Review. Press.

Mulyana, D. (2010). Komunikasi Lintas Budaya. PT. Remaja Rosdakarya, Bandung

Nurdiani.N. (2014). Teknik Sampling Snowball Dalam Penelitian Lapangan. Jurnal ComTech, Vol.5 No 2 halaman 1113 yang diaskses pada tanggal 24 Septembr 2019 pada https://media.neliti.com/media/publications/165822-ID-teknik-sampling-snowball-dalampenelitia.pdf

Ritzer, G. (2012). Teori Sosiologi Dari Teori Sosiologi Klasik Sampai Perkembangan Mutakhir Teori Sosial Postmodern. Bantul: Penerbit Kreasi Wacana.

Riyanto, A.A. (2003). Desain Busana. Bandung: Penerbit Yapemda.

Rukajat, A. (2018). Pendekatan Penelitian Kualitatif. Yogyakarta: Deepublish.

Srivasta, R., \& Joshi, S. (2014). Relationship between Self-concept and Self- esteem in adolescents. International Journal of Advanced Research, Vol 2 No. 2, 36- 43. Diakses pada tanggal 19 Agustus 2019 pada http://www.journalijar.com/uploads/733_IJAR-2560.pdf

Trisnawati. T. Y. (2011). Fashion sebagai Bentuk Ekspresi Diri dan Komunikasi. Jurnal The Messenger. Vol. 3 No 1. 36-47. Diakses pada tanggal 27 September 2019 pada http://journals.usm.ac.id/index.php/the-messenger/article/view/268

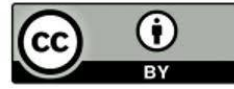


Venus, A. \& Helmi, L. (2010). Budaya Populer Jepang di Indonesia: Catatan Studi Fenomenologis Tentang Konsep Diri Anggota Cosplay Party Bandung, Jurnal Aspikom: 1(1): 71-88 diaksespada tanggal 15 Agustus 2019 pada http://journal.student.uny.ac.id/ojs/index.php/societas/article/viewFile/9099/8770.

Widodo, S. (2010). Anatomi dan Perkembangan Teori Sosial. Malang: Ditya Media. 